\title{
Does the fibromyalgia affect the quality of life in the patients with inflammatory bowel disease
}

\author{
๑Erdal Dilekçi ${ }^{1}$, @Güray Can ${ }^{2}$, ๑Müjgan Gürler ${ }^{3}$, ๑Esra Nur Ademoğlu Dilekçi ${ }^{4}, \oplus$ Meral Akdoğan Kayhan ${ }^{5}$ \\ ${ }^{1}$ Abant İzzet Baysal University, Physical Therapy and Rehabilitation Education and Research, Hospital, Department of Physical Therapy and \\ Rehabilitation, Bolu, Turkey \\ ${ }^{2}$ Abant İzzet Baysal University, Faculty of Medicine, Department of Gastroenterology, Bolu, Turkey \\ ${ }^{3}$ Abant İzzet Baysal University, Faculty of Medicine, Department of Internal Medicine, Bolu, Turkey \\ ${ }^{4}$ Abant İzzet Baysal University, Faculty of Medicine, Department of Endocrinology and Metabolism, Bolu, Turkey \\ ${ }^{5}$ Ankara City Hospital, Department of Gastroenterology, Ankara, Turkey
}

Cite this article as: Dilekçi E, Can G, Gürler M, Ademoğlu Dilekçi EN, Akdoğan Kayhan M. Does the fibromyalgia affect the quality of life in the patients with inflammatory bowel disease. J Health Sci Med 2021; 4(3): 377-382.

\begin{abstract}
Aim: Data on soft tissue rheumatism, especially fibromyalgia syndrome is limited in inflammatory bowel disease. Our aim in our study is to determine the prevalence of fibromyalgia syndrome and to evaluate the impact on quality of life in inflammatory bowel disease.

Material and Method: 60 ulcerative colitis and 34 Crohn's disease patients were included. 2010/2011 and 2016 American College of Rheumatology criteria were used for fibromyalgia syndrome diagnosis. A Fibromyalgia impact survey was applied to all patients.

Results: According to the American College of Rheumatology-2010/2011 criteria, fibromyalgia syndrome frequencies were determined as $29.8 \%$ in inflammatory bowel disease, $23.4 \%$ in Crohn's disease, and 33.3\% in ulcerative colitis (P>0.05). The frequency of fibromyalgia syndrome was significantly higher in inflammatory bowel disease and especially more in females. There was no significant difference between ulcerative colitis and Crohn's disease in terms of widespread-pain-index, somaticsymptom-severity, and fibromyalgia syndrome scores. Fibromyalgia impact scores were found significantly higher in those with fibromyalgia syndrome in inflammatory bowel disease, ulcerative colitis, and Crohn's disease.

Conclusions: This is the first study to show the frequency of fibromyalgia syndrome in patients with inflammatory bowel disease in the Turkish population. Fibromyalgia syndrome is increased in inflammatory bowel disease patients and more in ulcerative colitis and female. The quality of life is more affected in inflammatory bowel disease patients with fibromyalgia syndrome.
\end{abstract}

Keywords: Crohn's disease, fibromyalgia, inflammatory bowel disease, ulcerative colitis

\section{INTRODUCTION}

Inflammatory bowel disease (IBD) is a chronic, idiopathic inflammatory disease of the gastrointestinal tract that is accompanied by attacks, including two distinct diseases, Ulcerative colitis (UC) and Crohn's disease (CD). It mainly affects the gastrointestinal tract and causes a ratio of $40 \%$ extraintestinal complications (1). Articular, eye, skin, pulmonary and hepatobiliary system involvement is frequently seen. Joint involvement is the most common form of extraintestinal involvement in patients with IBD and its prevalence is between $17-39 \%(2,3)$. Studies involving musculoskeletal involvement in IBD are more focused on peripheral arthritis and spondylitis. Information on fibromyalgia syndrome (FMS), which is soft tissue rheumatism, is more limited (4). FMS is a chronic disease characterized by diffuse pain in the musculoskeletal system, sensitivity in specific anatomical points, and that accompanied by symptoms involving different systems such as fatigue, sleep disturbance, cognitive dysfunction, depressive attacks, irritable colon syndrome $(5,6)$. Although FMS is seen in all ages, it is most frequently encountered in the age range of 4060 years and 9-10 times more in females. Its prevalence has been reported between 2-8\% (7). Although the etiopathogenesis of FMS is not exactly known, it is thought that traumatic, inflammatory, immunologic, and hormonal factors, sleep disorders, depression, and anxiety 
are the main environmental factors based on genetic susceptibility that trigger this syndrome. In recent years, the contribution of hypothalamic-pituitary-adrenal axis disorder to pathophysiology has been also discussed (810). Nowadays, FMS syndrome is classified as 'central sensitivity syndromes' that central sensitization plays a role, with some diseases in its etiology, such as myofascial pain syndrome, chronic fatigue syndrome, migraine, restless legs syndrome, irritable bowel syndrome, tension-type headache, temporomandibular disorders, premenstrual syndrome (11). Since the pathophysiology of FMS is not clear, the treatment is difficult and requires a multidisciplinary approach (12). No study has been done in the Turkish population regarding the frequency of FMS in IBD, a chronic inflammatory disease. Conflicting results have also been reported in studies conducted in different societies. There is no data on the effect of FMS in the IBD on the quality of life. This study aims to determine the prevalence of FMS in IBD patients in the Turkish population and the effect on these patients' quality of life, which has been unrealized its etiopathogenesis and triggered by the chronic inflammatory process.

\section{MATERIALS AND METHODS}

\section{Ethical Issue}

After the study was planned, It was approved by Abant İzet Baysal University Non-Interventional Clinical Researchs Ethics Committee (Date: 11.01.2018, Decision No: 2017/182). Informed consent was obtained from all patients. The Turkish validity of the applied FMS impact survey (FIS) has previously been performed and there is free use of the survey (13).

\section{Patient Selection and Data Collection}

Over 16 years of age, $60 \mathrm{UC}$ and $34 \mathrm{CD}$, a total of 94 IBD patients who applied to Abant İzzet Baysal University Gastroenterology Clinic in the 2 months after the approval of the Ethics Committee; diagnosed by a gastroenterologist clinically, endoscopically, radiologically, and histopathologically and whose diagnosis have been confirmed by following-up for at least 3 months at our center, were included in our study. IBD patients diagnosed with FMS constituted the patient group, whereas IBD patients without FMS were determined as the control group. Clinical and sociodemographic characteristics of the patients were obtained from the patients themselves and their medical records.

\section{Diagnosis of Fibromyalgia}

For FMS diagnosis, 2010/2011 and 2016 American College of Rheumatology (ACR) criteria were separately used (14). For widespread body pain severity index (WSPI), questions were asked whether there was pain or tenderness within the last 7 days at the 19 spots indicated throughout the body. [1] points are given for each spot. The points of each spot giving a positive finding were added up and the WSPI score was calculated. The highest possible value for WSPI is 19. The somatic symptom weight scale (SSS) consists of two parts. In the first, three questions were asked such as fatigue, not being able to focus attention or difficulty in remembering, and not having rest when woken up in the morning. They were asked to express the severity of the symptoms of the disease within the last 7 days. Those who have no complaints [0 points], those who have mild or intermittent complaints [ 1 point], those whose complaints are moderate and frequently recurring [ 2 points], and those whose complaints are constant and affect their lives [3 points]. In the second part, in the last 6 months, they were asked if they have abdominal pain in the form of cramps in the lower abdomen area, depression, and headache. For each of these 3 findings [ 1 point] was given. By adding the scores of both parts, the total SSS score was calculated. The highest possible value for the SSS is 12. The FMS score was calculated from the addition of WSPI and SSS.

Besides, they were asked whether the pain and symptoms stated in WSPI and SSS were continuing at the same level in at least 3 months and whether other pathologies could explain these symptoms and pain. According to ACR2010/2011 criteria, FMS diagnosis was excluded if other pathologies would explain the symptoms and pain, or if it was shorter than 3 months. FMS was diagnosed when WSPI $\geq 7$ points and SSS $\geq 5$ points or WSPI 3-6 points and SSS $\geq 914$. According to ACR-2016 criteria the FMS diagnosis was established, if WSPI $\geq 7$ points and SSS $\geq 5$ points or WSPI 4-6 points and SSS $\geq 9$ points, there is a pain in at least 4 of the 5 areas; axial region, right and left arm, right and left leg. Pain and somatic symptoms are at the same level for at least 3 months, regardless of whether they have another disease to explain (15). Those who were diagnosed according to both criteria were shown separately. The FMS prevalence was calculated separately for men and women in both IBD and CD and UC.

\section{Fibromyalgia Impact Survey}

FIS was applied to IBD patients diagnosed with FMS and to IBD patients who do not have FMS as a control group (13). There are 10 questions in total in the FIS. The first question is related to physical disorders and consists of 11 sub-questions. They were asked to relate to what extent they can do 11 different activities such as washing, shopping. According to the answers given, the score of each question was determined; always [0 point], mostly [ 1 point], occasionally [ 2 points], and never [ 3 points]. The results were added and divided into 11 , the number of subquestions. Since the other questions (between questions 4 and 10) were evaluated on a 10 units scale, this result obtained was normalized by multiplying by 3.33 . In the second question, the patient was asked how many days he/ 
she felt well in the last week. Since the low value indicated that the disorder was excessive, the days when the patient felt bad about himself were taken into account. Therefore, the value that the patient marked was subtracted from 7. Since the other questions (between 4-10 questions) were evaluated out of 10 units, the result obtained was normalized by multiplying by 1.43 . In the third question, the high number indicates that the disorder is excessive. In the questions between 4 and 10, questions were asked about the degree of pain, fatigue, sluggishness in the mornings, getting up rested in the mornings, nervousness and depression, and to what extent the pain prevents their work. Since each question was evaluated out of 10, the value was noted without changing. By adding calculated values of each question, a total score was obtained. The total score can range from $0-100$. High scores indicate that the disease affects the patient more.

\section{Statistical Analysis}

Prevalence ratios were obtained by dividing the total number of cases (FMS) by the population at risk (IBD patients). SPSS 20.0 program (Armonk, NY: IBM Corp.) was used for statistical analysis. X2 test and Fisher's exact test were used to compare the ratios, and the Independent Student-t-test was used to compare the means. Statistically significant $(\mathrm{P})$ value was accepted as $<0.05$.

\section{RESULTS}

\section{Demographical and Clinical Characteristics}

No statistically significant difference was observed when the rates of $\mathrm{UC}$ and $\mathrm{CD}$ men and women were compared (for $\mathrm{UC}$ female/male ratio is $30 / 30$, for $\mathrm{CD}: 13 / 21 ; \mathrm{P}=0.27$ ). When the UC and CD patients were compared in terms of the means of age, they had a similar distribution. The demographic and clinical characteristics of patients are given in Table 1.

\begin{tabular}{|c|c|c|c|c|}
\hline & IBD & $\begin{array}{l}\text { Ulcerative } \\
\text { colitis }\end{array}$ & $\begin{array}{l}\text { Crohn's } \\
\text { disease }\end{array}$ & $\begin{array}{c}(\mathrm{P}) \\
\text { value }^{*}\end{array}$ \\
\hline Number (n) & 94 & 60 & 34 & \\
\hline Gender (F/M) & $43 / 51$ & $30 / 30$ & $13 / 21$ & 0.27 \\
\hline \multicolumn{5}{|c|}{ Age $($ year, mean $\pm S D)$} \\
\hline Total & $47.6 \pm 15.4$ & $46.3 \pm 15.5$ & $50.0 \pm 15.2$ & 0.25 \\
\hline Female & $45.4 \pm 14.7$ & $44.6 \pm 14.5$ & $47.4 \pm 15.6$ & 0.57 \\
\hline Male & $49.5 \pm 15.9$ & $47.9 \pm 16.6$ & $51.7 \pm 15.0$ & 0.41 \\
\hline (P) value $\dagger$ & 0.21 & 0.41 & 0.43 & \\
\hline \multicolumn{2}{|l|}{ Marital status n(\%) } & & & 0.80 \\
\hline Married & $79(84)$ & $50(83.3)$ & $29(85.3)$ & \\
\hline Single & $15(16)$ & $10(16.7)$ & $5(14.7)$ & \\
\hline $\begin{array}{l}\text { Extensive } \\
\text { involvement } \mathbf{n}(\%)\end{array}$ & $39(41.5)$ & $25(41.7)$ & $14(41.2)$ & 0.92 \\
\hline \multicolumn{3}{|l|}{ Disease activity $\mathbf{n}(\%)$} & & 0.52 \\
\hline Active & $17(18.1)$ & $12(20)$ & $5(14.7)$ & \\
\hline Remision & 77 (81.9) & $48(80)$ & $29(85.3)$ & \\
\hline $\begin{array}{l}\text { IBD: Inflammatory bowe } \\
\text { value }(P) \text { belonging to the } \\
\text { The value }(P) \text { of comparis } \\
\end{array}$ & $\begin{array}{l}1 \text { disease, F: Fer } \\
\text { e comparison } \mathrm{b} \\
\text { son between } \mathrm{m}\end{array}$ & $\begin{array}{l}\text { le, M: Male, SD } \\
\text { ween ulcerative } \\
\text { and women in }\end{array}$ & $\begin{array}{l}\text { tandard deviati } \\
\text { litis and Crohr } \\
\text { e same disease }\end{array}$ & $\begin{array}{l}\text { n. }{ }^{*} \text { The } \\
\text { s disease, } \dagger\end{array}$ \\
\hline
\end{tabular}

\section{Comparison of WSPI, SSS, and FMS Scores}

When WSPI, SSS, and FMS scores were compared separately, there was no significant difference between UC and CD, although scores were higher in UC (Table 2). When women and men were compared separately, yet, no significant difference was found between UC and CD. SSS and FMS scores were significantly found higher in women than in men with IBD and $\mathrm{CD}$ (respectively, $\mathrm{P}=0.001, \mathrm{P}=0.004$ for SSS; $\mathrm{P}=0.002, \mathrm{P}=0.017$ for $\mathrm{FMS}$ ). Although the SSS and FMS scores in the UC were higher in women, the difference was not significant. Although the WSPI score was higher in women with IBD, UC, and $\mathrm{CD}$, there was a significant difference only in IBD. (respectively; $\mathrm{P}=0.009, \mathrm{P}=0.104, \mathrm{P}=0.079$ ) (Table 2).

\begin{tabular}{|c|c|c|c|c|}
\hline & IBD & $\begin{array}{l}\text { Ulcerative } \\
\text { colitis }\end{array}$ & $\begin{array}{l}\text { Crohn's } \\
\text { disease }\end{array}$ & $\begin{array}{c}(\mathbf{P}) \\
\text { value }\end{array}$ \\
\hline \multicolumn{5}{|c|}{ WSPI (mean \pm SD) } \\
\hline Total & $4.70 \pm 4.3$ & $5.03 \pm 4.3$ & $4.12 \pm 4.4$ & 0.33 \\
\hline Female & $6.00 \pm 5.0$ & $5.93 \pm 4.6$ & $6.15 \pm 6.0$ & 0.89 \\
\hline Male & $3.61 \pm 3.3$ & $4.13 \pm 3.8$ & $2.86 \pm 2.4$ & 0.15 \\
\hline (P) value $\dagger$ & 0.009 & 0.104 & 0.079 & \\
\hline \multicolumn{5}{|c|}{ SSS $($ mean \pm SD) } \\
\hline Total & $4.53 \pm 3.3$ & $4.60 \pm 3.3$ & $4.41 \pm 3.3$ & 0.79 \\
\hline Female & $5.72 \pm 3.6$ & $5.33 \pm 3.6$ & $6.62 \pm 3.4$ & 0.28 \\
\hline Male & $3.53 \pm 2.7$ & $3.87 \pm 2.8$ & $3.05 \pm 2.5$ & 0.29 \\
\hline (P) value $\dagger$ & 0.001 & 0.084 & 0.004 & \\
\hline \multicolumn{5}{|c|}{ FMS score $($ mean $\pm S D)$} \\
\hline Total & $9.22 \pm 7.0$ & $9.62 \pm 6.8$ & $8.53 \pm 7.1$ & 0.47 \\
\hline Female & $11.70 \pm 7.8$ & $11.23 \pm 7.5$ & $12.77 \pm 8.6$ & 0.56 \\
\hline Male & $7.14 \pm 5.2$ & $8.00 \pm 5.7$ & $5.90 \pm 4.4$ & 0.16 \\
\hline (P) value $\dagger$ & 0.002 & 0.066 & 0.017 & \\
\hline
\end{tabular}

IBD: Inflammatory bowel disease, FMS: Fibromyalgia Syndrome, WSPI: widespread body pain index, SSS: Somatic symptom weight score, SD: standard deviation. ${ }^{\star} T$ The value of comparison $(\mathrm{P})$ between ulcerative colitis and Crohn's disease, $\uparrow$ The value of (P) comparison between men and women in the same disease.

\section{Prevalence of Fibromyalgia}

When compared with the prevalence of FMS (2\%) in the general population, the frequency of FMS was observed significantly increased in IBD, UC, and CD (respectively, $\mathrm{P}=0.0001, \mathrm{P}=0.0001, \mathrm{P}=0.0001)$. According to ACR2010/2011 criteria, The frequency of FMS was $29.8 \%$ in IBD, $23.4 \%$ in $\mathrm{CD}$, and $33.3 \%$ in $\mathrm{UC}$ and there was no significant difference compared to each other $(\mathrm{P}=0.32)$. When women and men were evaluated separately, the difference between $\mathrm{CD}$ and $\mathrm{UC}$ have not reached a significance level $(\mathrm{P}=0.82$ for women and $\mathrm{P}=0.68$ for men). The frequency of FMS in IBD, UC and CD was found significantly higher in women compared to in men (Female and male respectively, $48.8 \%-13.7 \%$ in IBD, $\mathrm{P}=0.0001 ; 50.0 \%-16.7 \%$ in UC, $\mathrm{P}=0.006 ; 46.2 \%-9.5 \%$ in $\mathrm{CD}, \mathrm{P}=0.033$ ) (Table 3). After evaluating according to ACR-2016 criteria, the obtained FMS prevalence values were given in Table 3. 


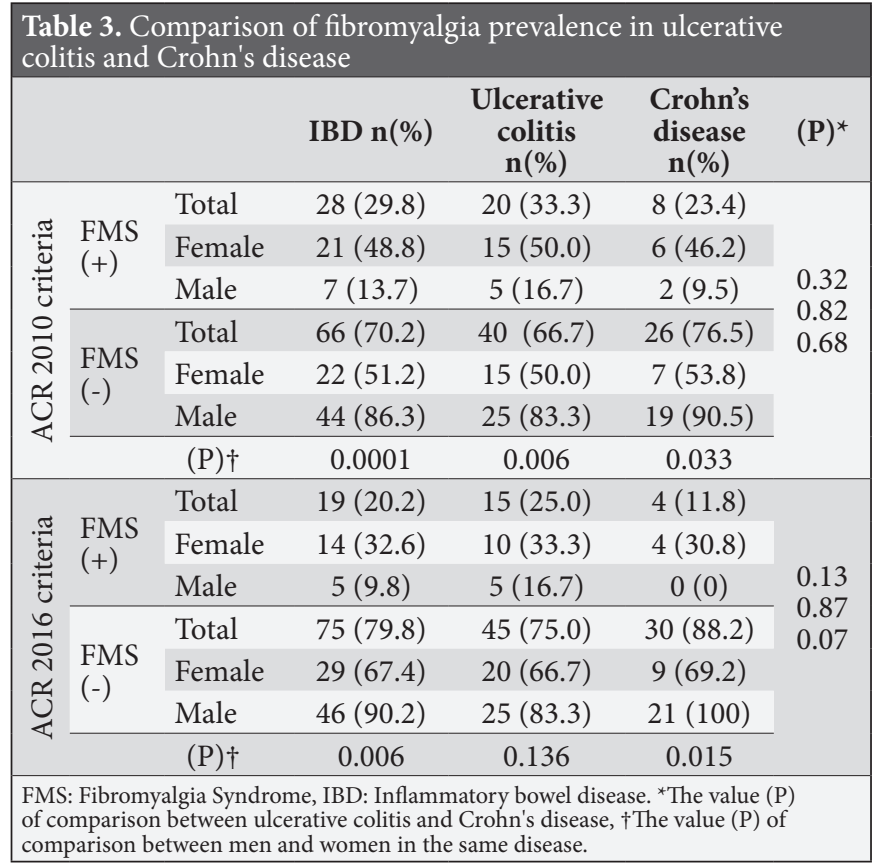

\section{Comparison of Fibromyalgia Impact Scores}

According to ACR-2010/2011 criteria; when those with FMS and non-FMS were compared in terms of FIS scores, significant differences were found in both the IBD, the UC, and the $\mathrm{CD}$ (respectively, $\mathrm{P}=0.0001$, $\mathrm{P}=0.0001, \mathrm{P}=0.0001)$. When women and men were evaluated separately, significance has been persisted for IBD, UC, and CD. FIS scores in those with FMS were evaluated before and after adjusted according to gender between the UC and CD, no significant difference was found statistically in both situations. When FIS scores were compared between females and males in IBD, UC, and CD separately, no statistically significant difference was found. There was no statistically significant difference between fibromyalgia impact scores in the non-FMS group of UC and CD before and after adjusted according to gender (Table 4). According to ACR-2016 criteria, FIS scores of patients who were diagnosed with FMS and those who have not been diagnosed with FMS were compared. Similar to the evaluation according to the ACR-2010/2011 criteria, when those with FMS and those with non-FMS were compared in terms of FIS scores, a statistically significant difference was found in the IBD, UC, and CD separately. Likewise, when females and males were evaluated separately, significance for IBD and UC was persisted. However, no comparison was made in male $\mathrm{CD}$ patients due to the absence of male patients who have not been diagnosed with FMS in CD. The results obtained were given in Table 4 .

\section{DISCUSSION}

FMS is the clinical condition defined in the group of soft-tissue rheumatism seen in the community with a prevalence of $2 \%$. It has been shown in females that the frequency increases at later ages, especially with chronic illnesses. In a study conducted in Turkey, FMS prevalence among women aged 20-64 was found to be 3.4\% (16). Psychological disorders, as well as physical symptoms of the disease, results in an impaired person's quality of life $(7,17)$. In literature, the frequency of FMS has been investigated in many chronic diseases and the studies that have been performed in the course of IBD are limited. In the study that they have carried out in 521 Scandinavian IBD patients, Palm and et al. (18) reported that the incidence of FMS was similar to the normal population and FMS was significantly higher in women than in men $(6.4 \%$ vs $0.4 \%)$. There was no statistically significant difference in terms of frequency of FMS in UC and CD (3.7\% vs $3.5 \%)$. In terms of WSPI a statistically significant difference between the general population and $\mathrm{UC} / \mathrm{CD}$ was not reported. In the study that they have been carried out, Bulska and et al. investigated the frequency of FMS in $72 \mathrm{UC}$ and $41 \mathrm{CD}$ patients and reported that more

Table 4. Comparison of the impact of fibromyalgia on the quality of life in ulcerative colitis and Crohn's disease

\begin{tabular}{|c|c|c|c|c|c|c|c|c|c|}
\hline & & & \multicolumn{2}{|l|}{ IBD } & \multicolumn{2}{|c|}{ Ulcerative colitis } & \multicolumn{2}{|c|}{ Crohn's disease } & \multirow[b]{2}{*}{$(\mathbf{P})^{\star}$} \\
\hline & & & $\begin{array}{c}\text { FMS impact } \\
\text { score }(\text { mean } \pm S D)\end{array}$ & $(\mathbf{P}) \dagger$ & $\begin{array}{c}\text { FMS impact } \\
\text { score }(\text { mean } \pm S D)\end{array}$ & $(\mathrm{P}) \dagger$ & $\begin{array}{c}\text { FMS impact } \\
\text { score }(\text { mean } \pm \text { SD })\end{array}$ & $(P) \dagger$ & \\
\hline \multirow{5}{*}{ 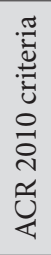 } & \multirow{3}{*}{$\begin{array}{l}\text { FMS } \\
(+)\end{array}$} & Total & $58.51 \pm 15.3$ & 0.0001 & $58.69 \pm 14.1$ & 0.0001 & $58.05 \pm 19.0$ & 0.0001 & 0.92 \\
\hline & & Female & $59.40 \pm 15.4$ & 0.0001 & $60.15 \pm 13.0$ & 0.0001 & $57.53 \pm 21.7$ & 0.001 & 0.74 \\
\hline & & Male & $55.82 \pm 15.9$ & 0.0001 & $54.31 \pm 18.0$ & 0.0001 & $59.61 \pm 13.6$ & 0.0001 & 0.73 \\
\hline & \multirow{2}{*}{$\begin{array}{l}\text { FMS } \\
(-)\end{array}$} & Total & $12.52 \pm 8.9$ & & $13.44 \pm 9.9$ & & $11.11 \pm 7.2$ & & 0.33 \\
\hline & & Male & $13.67 \pm 9.2$ & & $16.10 \pm 9.9$ & & $10.97 \pm 7.8$ & & 0.09 \\
\hline \multirow{5}{*}{ 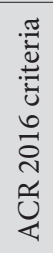 } & \multirow{3}{*}{$\begin{array}{l}\text { FMS } \\
(+)\end{array}$} & Total & $58.80 \pm 16.8$ & 0.0001 & $58.35 \pm 14.2$ & 0.0001 & $60.48 \pm 27.3$ & 0.0001 & 0.83 \\
\hline & & Female & $60.40 \pm 16.7$ & 0.0001 & $60.37 \pm 12.4$ & 0.0001 & $60.48 \pm 27.3$ & 0.027 & .99 \\
\hline & & Male & $54.31 \pm 18.0$ & 0.0001 & $54.31 \pm 18.0$ & 0.0001 & - & - & - \\
\hline & \multirow{2}{*}{$\begin{array}{l}\text { FMS } \\
(-)\end{array}$} & Total & $18.61 \pm 18.2$ & & $19.23 \pm 18.7$ & & $17.71 \pm 17.7$ & & 0.74 \\
\hline & & Female & $22.53 \pm 23.0$ & & $22.35 \pm 24.5$ & & $23.05 \pm 20.0$ & & 0.95 \\
\hline
\end{tabular}


frequent in CD and 30\% in IBD (49\% in CD, 19\% in UC). WSPI was reported higher in CD patients (4). Palm and et al. have found the frequency of FMS higher in patients with UC, whereas Bulska and et al. (19) reported that CD and FMS were seen together more frequently. In the study that has been performed in 651 IBD patients from Italy; the frequency of FMS has been found $0.2 \%$ in the UC and $1.1 \%$ in $\mathrm{CD}(\mathrm{P}>0.05)$. The FMS frequency was reported similar to the general population. FMS frequency was reported to be $2.1 \%$ in CD and $1.1 \%$ in UC in the Iranian population, similar to the normal population (20). In these two studies, although FMS was more frequent in CD, there was no increase in the group of IBD according to the normal population. ACR-1990 criteria have been used in the studies conducted in the literature for FMS diagnosis, while ACR-2010/2011 criteria have been used in our study for FMS diagnosis. In our study, the frequency of FMS increased in the IBD compared to the general population and was found $29.8 \%$. The difference between the two groups of patients was not found statistically significant, although it was more frequent in UC patients $(33.3 \%$ in UC, $23.4 \%$ in CD). In our study, both FMS frequency and FIS scores were significantly higher in females in the groups of IBD, UC, and CD. The conflict between the results in the literature and our study was thought to be due to differences in the geographical region, ethnicity, and genetic background. Besides, according to ACR2010/2011 criteria; together with the FMS score, WSPI and SSS scores have been evaluated separately. Although there was no significant difference between CD and UC, scores of SSS and FMS in IBD and CD, and WSPI scores in IBD were found higher in women.

As is known, ACR-1990 diagnostic criteria have been used in the FMS diagnosis throughout the years (5). However; having not defined the widespread pain adequately in these criteria and having used sensitive points that often vary the number according to their stress state in patients, have led to forming of the ACR-2010 criteria (14). In these criteria, the sensitive points were not assessed and somatic symptoms were questioned. In 2011, these criteria were revisited by the ACR and the somatic symptom weight scale was modified by revising and added to the widespread pain index (21). Wolfe and et al. have published the ACR-2016 criteria, arguing that false-positive FMS cases are increasing due to the lack of sensitive point examination (15). In the study that they carried out, Ablin and et al. (22) have also shown that $7-13 \%$ of FMS diagnoses have not met new criteria under ACR-2010/2011 criteria. In our study, we have evaluated our patients according to both ACR-2010/2011 and ACR2016 criteria, and we have sought to answer the question of whether there are differences in FMS frequency and FIS scores when different diagnostic criteria are used. According to the ACR-2010/2011 criteria, the prevalence of FMS was $29.8 \%$ in IBD, 9.6\% lower than in ACR-2016 criteria, and found $20.2 \%$. According to both criteria, FMS was more frequent in females but this difference was not found significant according to ACR-2016 criteria. Moreover, when evaluated according to ACR2016 criteria, the FMS prevalences in UC and CD were found to be the ratio of $8.3 \%$ and $11.6 \%$ lower following the ACR-2010/2011 criteria. The results obtained are consistent with the results obtained by Ablin et al. (22).

FIS is generally used to measure the effects of the disease on daily life in FMS. FIS, in addition to the functional status of the patients in FMS, helps to assess disease severity by questioning parameters such as pain, fatigue, sluggishness in the morning, anxiety, and depression $(23,24)$. Sarmer and et al. (24) have revealed that the Turkish version of FIS is valid and reliable. In the literature, no studies are evaluating the association of IBD and FMS in the Turkish population. In our study; according to ACR-2010/2011 criteria; It has been shown that FMS-related quality of life was more affected in IBD, UC, and CD patients who were diagnosed with FMS than non-FMS patients. In our study, although FMS has been found more frequently in female patients, in both genders the disease has affected significantly the quality of life. Similar results were also obtained to be when evaluated according to ACR-2016 criteria. However, due to the absence of a male patient with a diagnosis of FMS in CD, this group of patients has not been able to evaluate.

The limitations of our study are that the number of patients taken into the study was few, the fact that the patient population is consisted of follow-up patients in the tertiary healthcare institution and does not reflect the IBD patients generally, according to the criteria of ACR2016, inability to reach a judgment in this group due to the absence of a patient diagnosed with FMS in CD, There is a need for a community-based study involving more IBD patients so that the results obtained can be confirmed more reliably.

\section{CONCLUSION}

As a result, our study is important in terms of being the first study evaluating the association of IBD and FMS in Turkish society and the impact of FMS on the quality of life in IBD. Meanwhile, in this study, FMS presence in IBD patients was assessed with ACR-2010/2011 criteria as well as ACR-2016 criteria, and the differences between the diagnostic criteria were demonstrated. In our study; as it is in the course of other chronic diseases, its frequency is higher in the UC and female patients. When different diagnostic criteria were used in IBD, we tried to sought to answer the question as to whether there was a change in the frequency of FMS. Also, it has been shown that FMS significantly affects the quality of life in IBD patients. 


\section{ETHICAL DECLARATIONS}

Ethics Committee Approval: After the study was planned, It was approved by Abant İzzet Baysal University, Non-Interventional Clinical Researchs Ethics Committee (Date: 11.01.2018, Decision No: 2017/182).

Informed Consent: Written informed consent was obtained from all participants who participated in this study.

Referee Evaluation Process: Externally peer-reviewed.

Conflict of Interest Statement: The authors have no conflicts of interest to declare.

Financial Disclosure: The authors declared that this study has received no financial support.

Author Contributions: All of the authors declare that they have all participated in the design, execution, and analysis of the paper and that they have approved the final version.

\section{REFERENCES}

1. Ott C, Schölmerich J. Extraintestinal manifestations ve complications in IBD. Nat Rev Gastroenterol Hepatol 2013; 10: 585-95.

2. Arvikar SL, Fisher MC. Inflammatory bowel disease-associated arthropathy. Curr Rev Musculoskelet Med 2011; 4: 123-31.

3. Peluso R, Di Minno MND, Lervolino S, et al. Enteropathic spondyloarthritis: from diagnosis to treatment. Clin Dev Immunol 2013; 2013: 631408.

4. Buskila D, Odes LR, Neumann L, Odes HS. Fibromyalgia in inflammatory bowel disease. J Rheumatol 1999; 26: 1167-71.

5. Wolfe F, Smythe HA, Yunus MB, et al. The American College of Rheumatology 1990 Criteria for the classification of fibromyalgia. Report of the Multicenter Criteria Committee. Arthritis Rheum 1990; 33: 160-72.

6. Bennett RM, Jones J, Turk DC, Russell IJ, Matallana L. An internet survey of 2596 people with fibromyalgia. BMC Musculoskelet Disord 2007; 8: 27.

7. Wolfe F, Ross K, Anderson J, Russel IJ. Aspects of fibromyalgia in the general population: sex, pain threshold, and fibromyalgia symptoms. J Rheumatol 1995; 22: 151-6.

8. Bradley LA. Pathophysiology of fibromyalgia. Am J Med 2009; 122: 22-30.

9. Calıs M, Gökce C, Ates F, et al. Investigation of the hypothalamicpituitary-adrenal axis (HPA) by $1 \mu \mathrm{g}$ ACTH test and metyrapone test in patients with primary fibromyalgia syndrome. J Endocrinol Invest 2004; 27: 42-6.

10. Crofford LJ, Pillemer SR, Kalogeras KT, et al. Hypothalamicpituitary-adrenal axis perturbations in patients with fibromyalgia. Arthritis Rheum 1994; 37: 1583-92.

11. Yunus MB. Fibromyalgia and overlapping disorders: the unifying concept of central sensitivity syndromes. Semin Arthritis Rheum 2007; 36: 339-56.

12. Hauser W, Thieme K, Turk DC. Guidelines on the management of fibromyalgia syndrome-a systematic review. Eur J Pain 2010, 14: 5-10.

13. Burckhardt CS, Clark SR, Bennett RM. The fibromyalgia impact questionnaire: development and validation. J Rheumatol 1991; 18: 728-34.
14. Wolfe F, Clauw DJ, Fitzcharles MA, et al. The American College of Rheumatology preliminary diagnostic criteria for fibromyalgia and measurement of symptom severity. Arthritis Care Res (Hoboken) 2010; 62: 600-10.

15. Wolfe F, Clauw DJ, Fitzcharles MA, et al. 2016 Revisions to the 2010/2011 fibromyalgia diagnostic criteria. Semin Arthritis Rheum 2016; 46: 319-29.

16. Topbaş M, Çakırbay H, Güleç H, Akgol E, Ak I, Can G. The prevalence of fibromyalgia in women aged in Turkey. Scand J Rheumatol 2005; 34: 140-4.

17. Clauw DJ. Fibromyalgia: An overview. Am J Med 2009; 122: 3-13.

18. Palm O, Moum B, Jahnsen J, Gran JT. Fibromyalgia and chronic widespread pain in a population in patients with inflammatory bowel disease: a cross-sectional population survey. J Rheumatol 2001; 28: 590-4.

19. D’Incà R, Podswiadek M, Ferronato A, Punzi L, Salvagnini M, Sturniolo GC. Articular manifestations in inflammatory bowel disease patients: a prospective study. Dig Liver Dis 2009; 41: 5659

20. Fatemi A, Jazi HH, Emami MH, Kazemizadeh A, Tavakkoli H, Smiley A. Relationship between articular and nonarticular manifestations in inflammatory bowel diseases. J Res Med Sci 2016; 14: 48 .

21. Wolfe F, Clauw DJ, Fitzcharles MA, et al. Fibromyalgia criteria and severity scales for clinical and epidemiological studies: a modification of the ACR preliminary diagnostic criteria for fibromyalgia. J Rheumatol 2011; 38: 1113-22.

22. Ablin JN, Wolfe F. A comparative evaluation of the 2011 and 2016 criteria for fibromyalgia. J Rheumatol 2017; 44: 1271-6.

23. Burckhardt CS, Clark SR, Bennett RM. The fibromyalgia impact questionnaire: development and validation. J Rheumatol 1991; 18: 728-33.

24. Sarmer S, Ergin S, Yavuzer G. The validity and reliability of the Turkish version of the fibromyalgia impact questionnaire. Rheumatol Int 2000; 20: 9-12. 